\title{
A Longitudinal Analysis of Stress in African American Youth: Predictors and Outcomes of Stress Trajectories
}

\author{
Karen H. Schmeelk-Cone ${ }^{1}$ and Marc A. Zimmerman ${ }^{2}$
}

Received 17 June, 2002; revised 12 August 2002; accepted 24 November, 2002

Few researchers have studied trajectories of stress over time in relation to psychosocial outcomes and behaviors among adolescents. A sample of African American adolescents were assessed longitudinally on perceived stress, psychological well-being, support, antisocial behaviors, and academic success. Patterns of stress over 4 time points were developed using a cluster-analytic approach. Differences among the trajectory clusters were examined using psychosocial outcomes and behaviors. Adolescents with chronic levels of stress reported more anxiety and depression, engaged in antisocial behaviors, and reported less active coping than youth in other trajectories. Adolescents with low levels of stress over time reported fewer psychological problems, perceived more social support, and were more likely to graduate from high school than those with higher stress levels over time. We also found that an increase in stress coincided with a lack of support and more psychological problems over time.

KEY WORDS: adolescents; stress; African-American; longitudinal analysis.

\section{INTRODUCTION}

Psychological stress is generally conceptualized as either an acute state in relation to a life event or a chronic state based on a set of events or circumstances in one's life (Chrousos and Gold, 1992; Cohen, 1988). Few researchers, however, have examined patterns of perceived stress over time among adolescents. It is likely, for example, that some individuals would report consistently high stress, while others would report consistently low stress, and others would report a changing pattern over

\footnotetext{
${ }^{1}$ Senior Research Associate, Department of Health Behavior and Health Education, School of Public Health, University of Michigan. Received $\mathrm{PhD}$ in Biobehavioral Health at the Pennsylvania State University. Interested in the relationships between both perceived and physiological measures of stress, and psychological well-being and antisocial behavior in adolescents and young adults.

${ }^{2}$ Professor, Department of Health Behavior and Health Education, School of Public Health, and Psychology, University of Michigan. Received PhD in Psychology at the University of Illinois, Champaign. Research interests include adolescent health and resiliency and empowerment theory. Also Director of the Prevention Research Center of Michigan, and the Youth Violence Prevention Center. To whom correspondence should be addressed at Department of Health, Behavior and Health Education, School of Public Health and Psychology, University of Michigan, Michigan; e-mail: marcz@umich.edu.
}

time. Little research has examined these individual differences in patterns of change over time and the psychosocial antecedents or consequences of different stress trajectories. One goal of the present study is to begin a program of research on this issue.

\section{Stress and Adolescent Development}

Stress is a vital health concern that affects many mental and physical outcomes at all ages. Several factors in adolescents' lives may be stressors, including exposure to violence, peer pressure, poverty, and school. A study of the effects of exposure to violence (stressor) on anxiety indicated that girls with high initial exposure rates had increased difficulty concentrating and boys with low exposure had more problems concentrating (White et al., 1998). Stress is also generally related to problem behaviors in young adolescents (McCabe et al., 1999). Health problems and disease states have also been related to stress, particularly cardiovascular disease. Jackson et al.'s study of adolescents (Jackson et al., 1999) with a family history of hypertension found that African Americans have a greater physiological reactivity to the same stressors as whites. High SES African Americans also have higher diastolic blood pressure than low SES African Americans, 
which is opposite to the pattern generally found in whites (Jackson et al., 1999). This higher reactivity and baseline blood pressure tends to be related to development of cardiovascular diseases. Additionally, chronic stress is related to alterations in the functioning of the hypothalamicpituitary-adrenal (HPA) axis, causing hypo- or hypersecretion of cortisol. Activation of the HPA axis results in increased glucose in the blood, increased heart rate, blood pressure, enhanced arousal, promotion of cautious restraint, and inhibition of vegetative functions (Chrousos and Gold, 1992). Thus, cortisol levels at any particular time are related to a person's level of stress and can have significant consequences on health. Depression, anxiety, externalizing behaviors, internalizing behaviors, and conduct disorder have been associated with cortisol levels (McBurnett et al., 2000; Scerbo and Kolko, 1994; Susman et al., 1996, 1997). The influence of cortisol on specific brain areas may suggest a mechanism for the effects of stress on psychological well-being and behaviors.

Some individuals may face increased risks because of having inherently greater levels of stress. Racial minority status has been postulated to be a stressor because of increased exposure to prejudice, discrimination, and hostility as compared to individuals with majority status (Smith, 1985). In fact, several studies have shown African American adolescents report more stressful events than whites (Dornbush et al., 1991; Weist et al., 1995). Researchers have not only reported higher rates of stress among racial minority groups, but also found that the consequences of stress for psychological and physical health may be greater for some minority groups. Miller (1999) found that stress caused by a hostile environment (i.e., racial discrimination) affects risks for mental and physical disorders among African Americans. Racial differences in stress-related cardiovascular reactivity may account for the increased rates of hypertension and stroke, and use of alcohol to relieve stress may account for disparities in kidney disease rates. African Americans are 2-4 times more likely to develop hypertension by age 50,3-4 times more likely to suffer stroke, $2-5$ times more likely to develop end-stage kidney disease than whites (James, 1994). When ethnic or racial groups are a small proportion of the total population in an area, diagnosed rates of mental illness are higher in these minority groups than in the majority group, even when social class is controlled (Smith, 1985). African Americans' experiences of racial discrimination and the perceived stress from this discrimination have been related to poorer mental health outcomes (Landrine and Klonoff, 1996). African Americans, in general, may be more at risk for mental health problems due to racial discrimination than whites or other minority groups. Thus, exposure to stress may have a particularly detrimental effect on both physical and mental health for African American adolescents.

Gender may also play a role in the association between stress and both psychological and behavioral outcomes. In a sample of urban adolescents, life event stress was related to behavior problems for boys without any moderation by locus of control, family environment, social support or coping style (Weist et al., 1995). For girls, Weist et al. found the effect of stress on behavior problems was moderated by problem-focused coping, where the relation between stress and behavior problems was greater with less coping. In a highly stressed sample of urban children, however, no gender differences were found in the relations of aggressive behavior to parent characteristics, child IQ, school problems, and peer relationships (Sutton et al., 1999). In the following review, we point out effects of gender when examined to further emphasize that analysis of gender differences in responses to stress may be necessary.

\section{Psychosocial Outcomes and Behaviors Associated With Stress}

Researchers have found that both personality characteristics and social support may be associated with stress resistance (Dornbusch et al., 1991; DuBois et al., 1994; Licitra-Kleckler and Waas, 1993; Rutter, 1993; Windle and Windle, 1996). Windle and Windle found that stressful life events and negative daily events predicted more depression, while positive daily events predicted less depression in a sample of white high school students. High stress females also reported more depression than high stress males (Licitra-Kleckler and Waas, 1993). More daily hassles and major life events predicted later psychological distress in middle school youth, with an increasing effect of hassles when those with more socioeconomic disadvantage were selected (DuBois et al., 1994). Conger et al. (1994) also found that the stressor of economic hardship was related indirectly to internalizing symptoms for both boys and girls. While these studies all consistently document the negative effects of stressors on psychological well-being, they included predominantly (or all) white samples. Dornbusch et al. (1991) suggested that while African American adolescents were more stressed than whites, they had fewer psychological symptoms than white adolescents. In a study of 6th- to 8th-grade girls, Carlson et al. (2000) found a negative effect of family stress on self-esteem, which was mediated by ethnic identity in African Americans. This mediation by ethnic identity may relate to racial differences in the effect of stress on psychological well-being. 
Another factor that may be associated with stress resistance in some populations of African Americans is active coping. John Henryism is a form of active coping characterized by efficacious mental and physical vigor, strong commitment to hard work, and a single-minded determination to succeed (James, 1994). The relationship between John Henryism and stress, however, is complex because it may be a risk factor for poor outcomes for some and a protective factor for others. James et al. (1983, 1987, 1992) found that respondents with higher blood pressure and other cardiovascular indicators of stress included those with either high John Henryism and low SES or low John Henryism and high SES. The link between stress and hypertension in African Americans may be due to this prolonged, high effort coping with psychosocial stressors (James, 1994). John Henryism is also associated with increasing systolic blood pressure (SBP) for men and decreasing SBP for women. Women with low John Henryism are more than twice as likely to be hypertensive as women with high John Henryism scores (Dressler et al., 1998). While previous research included adult samples, this research suggests that John Henryism may be a relevant factor for understanding stress among African American adolescents, as well. Research examining John Henryism and stress longitudinally would be particularly beneficial because most of the research is cross-sectional.

Social support has been widely studied as an asset for reducing the negative effects of stress (for detailed review, see Cohen, 1988). Researchers have consistently found buffering and main effects of social support (Cohen, 1988). Stress effects on the cardiovascular, endocrine and immune systems may be affected by social support, especially emotional support (Uchino et al., 1996). In a study of male, African American adolescents, however, no support for a stress-buffering effect of emotional support for stressful life events was found (Zimmerman et al., 2000). Zimmerman et al. (2000) suggest that stressful life events may have a more immediate effect on adolescents, but minimal lasting consequences. Windle and Windle (1996) did not find evidence for the stress-buffering effects of family emotional support in a sample of 11th- and 12thgraders. In a household study of social support and hypertension in North Carolina, Strogatz and James (1986) found African Americans were more likely to report low instrumental support (defined here as help and the likelihood of help with tangible problems), and twice as likely to be classified with low emotional support than whites. Additionally, in households with an income less than $\$ 10,000$, low instrumental support was related to the prevalence of hypertension, but these effects were not found for whites (Strogatz and James, 1986). These studies suggest that social support may not have buffering effects for adolescents, but may have direct effects on perceived stress or on reducing the negative consequences of stress on several psychosocial outcomes. Yet, much of this research was cross-sectional or included only 2 time points, and not all the research clearly defined the type of support examined. Research that examines how specific types of social support may influence chronic stress longitudinally is necessary to more fully understand the link between perceived stress and social support.

Antisocial behaviors may also be a critical factor for understanding stress among adolescents. Adolescents may engage in antisocial behaviors to relieve stress, or involvement in these behaviors may increase stress. Tolan (1988) found that different types of stressors, such as circumscribed events, daily hassles, and developmental transitions, were related to delinquency in a study of mostly white adolescents. Yet, developmental transitions only predicted delinquency in girls, while no type of stressor predicted delinquency for boys (Tolan, 1988). Conversely, Licitra-Kleckler and Waas (1993) found females reported more stressful life events than males, but high stress males showed a greater variety and frequency of delinquency, more school and family problems, and committed a greater variety and frequency of serious crime than females. Windle and Windle (1996) also found stressful life events and positive daily events predicted higher levels of alcohol use and problems, and delinquent activities. Adolescents with a history of sexual offences and conduct disorders had the same levels of daily stress as control adolescents (Hastings et al., 1997), but this may be due to the fact that the offenders were in treatment at the time of the assessment. A limitation of these studies, however, is that all included predominantly (or completely) white samples.

The relationship between stress and delinquency is less clear in the African American population. Dornbusch et al. (1991) noted that African American youth reported more stress, but also less deviance than white adolescents in their sample. In a more ethnically diverse sample, the stressor of economic hardship was shown to have no direct effect on delinquency, but an indirect effect through parent-child attachment, involvement, and control was found among whites (Smith and Krohn, 1995). Economic hardship did not directly affect any of the mediators of delinquency among the African Americans in the sample (Smith and Krohn, 1995). Conversely, McCabe et al. (1999) found stress was generally related to problem behaviors in early-adolescent African American youth. One reason for these disparate findings may be the different measures of stress used. Smith and Krohn (1995) examined family economic background, Dornbusch et al. (1991) used a scale of a number of stressful events, 
while McCabe et al. (1999) used a composite score of socioeconomic risk and family stressful events. While all such scales examine stress on a global level, the effect of economic stress is more likely to be chronic in nature, whereas life events may be more acute, accounting for disparities in findings.

Other vital outcomes to study in relation to perceived stress are related to academic success. Higher stress in African Americans was posited to be related to their lower grades relative to whites (Dornbusch et al., 1991). Windle and Windle (1996), for example, found stressful life events and negative daily events predicted lower grade point average (GPA), while positive daily events predicted higher GPA in their sample of white high school students. In a study of 10th-graders of Mexican descent, Gillock and Reyes (1999) reported lower GPA was predicted by more stressful life events concerning friends, chronic personal and school stressors, and fewer school life events among females. For boys, however, less friend chronic stressors and more school chronic stressors predicted a lower GPA (Gillock and Reyes, 1999). Neither daily hassles nor major life events predicted grades for a mixed race sample of 7th- and 8th-graders when the previous semester's grades were controlled (DuBois et al., 1994). Thus, while stress may be related to lower grades, this relationship may be overshadowed by the effects of previous grades.

Research on stress and psychosocial outcomes suggests a dearth of information regarding African American youth. In addition, most of the studies were cross-sectional or included only 2 time points, and do not examine patterns of perceived stress over time. The influence of stress during adolescence is especially relevant because it is associated with several negative outcomes during this developmental period, and may also have implications for adult physical and mental health. Our study examines stress over 4 annual measurements, allowing us to examine patterns of chronic and acute stress. While some studies included multiple measures of stress (e.g., daily hassles and life events), the measures could not adequately examine change or assess patterns in stress over time. Our study begins by examining what, if any, patterns exist across 4 time points. We then examine how individuals with different patterns may differ on psychological well-being, social support, delinquency, and academic success. This study includes a sample of African American adolescents assessed over a 5-year period. We expect to find differing patterns of perceived stress over time, and that psychosocial factors will be related in different ways for youth with varying stress trajectories. Gender differences in perceived stress or psychosocial factors may also play a role, and will be tested in our models.

\section{METHODS}

\section{Sample}

Participants included 421 African American adolescents (58\% female) who participated in all of the first 5 waves of a longitudinal study of school dropout and drug use in a large Midwestern city. This represents a $61.8 \%$ response rate from the original (1994) sample of 681 African American youth. Selection criteria were (1) having an initial GPA of 3.0 or lower and (2) not being diagnosed by the schools as emotionally impaired or developmentally disabled.

\section{Procedure}

Data were collected in 5 waves. At Wave 1 (1994), all participants were in the 9th grade, but stress was not measured until Wave 2. Participants were reinterviewed for the next 3 years at 1 -year intervals whether they were in or out of school. Wave $5(1999 / 2000)$ data were collected approximately 2 years after Wave 4 . Structured, face-toface interviews were conducted with students in school during school hours, or in a community setting if the participants could not be found in school. Wave 5 interviews were completed in a community setting or the respondent's home. The interviews lasted 50-60 min. When the interview portion was done, participants completed a selfadministered paper and pencil questionnaire about drug and alcohol use, and other sensitive information. Participants were informed that all information was confidential and subpoena-protected.

\section{Measures}

Stress

The Perceived Stress scale was used to measure stress (Cohen et al., 1983). This scale consists of 11 items assessing how many times in the last month the respondent, for example, felt stressed, felt in control, or had problems dealing with responsibilities. The items were rated on a 5-point Likert scale (never to very often) and were coded such that higher scores denote more stress. This scale was added to the questionnaire in Wave 2 and was used in all successive years. Cronbach's alpha for our sample ranged from 0.74 to 0.83 .

\section{Psychological Well-Being}

Depression and anxiety were assessed using the Brief Symptom Inventory (Derogatis and Spencer, 1982). The 
6-item depression and anxiety subscales have Cronbach's alphas of $0.78-0.86$ and $0.79-0.88$ over the 5 waves, respectively, in our sample.

The John Henryism scale was used to measure active coping (James et al., 1987). This 8-item measure includes items such as, "Hard work is the best possible way for someone to get ahead in life." and "Sometimes I feel that if anything is going to be done right, I have to do it myself." The measure uses a 5-point Likert scale (not true to very true). The Cronbach's alpha for this scale ranged from 0.70 to 0.84 over 5 waves in our sample.

\section{Support}

Parental support was measured using the 5 items from Procidano and Heller's parent's support scale (Procidano and Heller, 1983). This version was used at Wave 1, but for successive waves the items were modified by changing the word parents to mother and father and calculating the support from each parent separately. The items used a 5-point Likert scale (not true to very true). The Cronbach alpha for parent support at Wave 1 was 0.89 , and the alphas for mother and father support over the other 4 waves ranged from 0.88 to 0.93 and 0.93 to 0.94 , respectively.

\section{Delinquency}

We assessed frequency of violent behavior (seven items) and frequency of nonviolent delinquent behavior (10 items) over a period of 12 months rated on a 5-point scale ( 0 times to 4 or more times). Violent behavior consisted of behaviors such as getting into a fight, or using a knife or a gun. Nonviolent delinquency consisted of behaviors such as stealing, damaging property, or trespassing. The Cronbach's alpha for these scales over time were $0.68-0.80$ for violent behaviors, and $0.83-0.84$ for nonviolent behaviors.

\section{Academic Success}

At Waves 1-4, academic success was measured by school-reported GPA and self-reported grades (on a 9point scale, A, A-, B+, B, B-, C+, C, C-, D). At Wave 5, academic success was measured by an item asking the highest grade completed (10th-12th, GED, high school diploma, 1-3 years of college) and a measure of school reported graduation status with $1=$ no diploma or GED and not currently attending school, $2=$ received GED or in school for GED or diploma, $3=$ received high school diploma.

\section{Data Analytic Strategy}

Cluster analysis was used to create stress trajectory groups over Waves 2 through 5. The method used was Ward's method, with intervals measured by squared Euclidian distance. Clusters were determined by examining the dendogram and the agglomeration schedule. These groups were examined for sex differences prior to analyses. To test the differences between groups on predictor and outcome variables, multivariate $2(\operatorname{sex}) \times 4$ (cluster) ANOVA was used at Wave 1 and Wave 5.

\section{RESULTS}

\section{Cluster Analysis}

The total sample, when examined by repeated measures ANOVA showed a linear decreasing effect over time $(F(1,438)=21.827, p<0.001)$, with a mean change of 0.17 units (Wave 2 mean $=2.54$, Wave 5 mean $=2.37$ ). To determine patterns of stress over time (Waves 2-5), we used cluster analysis to group cases on the basis of similarity of the 4 waves of stress data. Four clusters were determined and classified as follows: high at all time points (High, $n=32 ; 8 \%$ ), low at all time points (Low, $n=128$; $30 \%)$, starting at a moderate level and increasing over time (Increasing, $n=140 ; 33 \%$ ) and starting at a moderate level and decreasing over time (Decreasing, $n=121$; $29 \%$ ). Using a one-way analysis of variance, all stress trajectory groups had different levels of stress from each other at each time point except the Increasing and Decreasing groups at Waves 2 and 3 (by Scheffe post hoc analyses). This suggests a clear identity for the clusters based on Raine and colleagues' (1990) suggested method (Raine et al., 1990). Mean stress levels for each group at each time are graphed in Fig. 1.

We found that males and females were not equally represented across cluster groups $\left(\chi^{2}(3)=25.506, p<\right.$ $0.001)$. Males were more likely to be in the Low group than females and more females were found in the remaining 3 groups than males. In analyses examining differences across all 4 groups, sex was included in $2 \times 4$ factorial designs. Sex was not controlled for in specific analyses comparing the Increasing and Decreasing groups because these groups had a similar proportion of males and females.

\section{Predictors of Stress Trajectories}

Two (sex) by four (stress group) MANOVAs were conducted for each set of the well-being, support, antisocial 


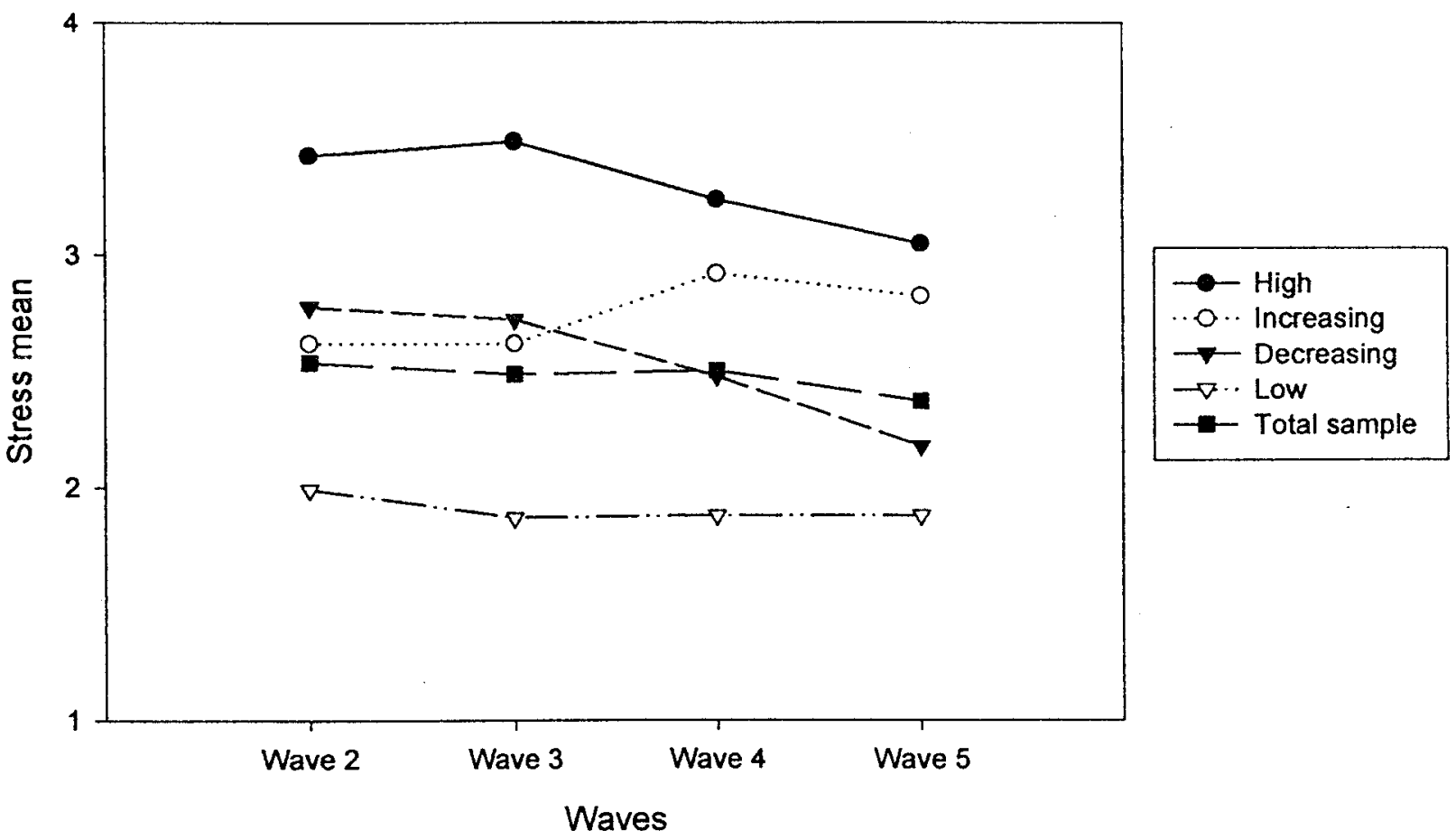

Fig. 1. Trajectories of mean stress over time.

behaviors, and academic success variables at Wave 1. The means and standard deviations for these analyses are reported in Table I.

\section{Psychological Well-Being}

We found no sex by cluster group interaction $(F(9,1172)=0.742$, ns $)$, but multivariate main effects were found for cluster group (Hotelling's Trace $F(9$, $1172)=2.109, p<0.05)$ and $\operatorname{sex}(F(3,392)=5.960$, $p<0.01)$. Univariate ANOVA main effects of cluster group were found for anxiety $(F(3,402)=4.920, p<$ $0.01)$ and depression $(F(3,402)=3.869, p<0.01)$, but not John Henryism. Those in the Low stress group reported lower levels of anxiety and depression than all the other groups. Females reported more anxiety $(F(1,402)=$ $10.775, p<0.01)$ and depression $(F(1,402)=16.587$, $p<0.01)$ than males.

Support

We found main effects for cluster (Hotelling's Trace $F(6,792)=3.707, \quad p<0.01)$ and $\operatorname{sex}(F(2,397)=$

Table I. MANOVA Means (and Standard Deviations) for Wave 1 Variables

\begin{tabular}{llllll}
\hline & \multicolumn{4}{c}{ Stress trajectory } \\
\cline { 2 - 6 } & \multicolumn{1}{c}{ Variable } & High & Increasing & Decreasing & Low \\
\hline \multirow{2}{*}{ Well-being } & Anxiety & $1.8656(.6971) \mathrm{a}$ & $1.6391(.6724) \mathrm{a}$ & $1.6020(.5889) \mathrm{a}$ & $1.3784(.4541) \mathrm{b}$ \\
& Depression & $2.0000(.8542) \mathrm{a}$ & $1.7368(.6933) \mathrm{a}$ & $1.7055(.6668) \mathrm{a}$ & $1.4503(.6741) \mathrm{b}$ \\
\multirow{3}{*}{ Support } & John Henryism & $3.9919(.5907) \mathrm{a}$ & $4.1758(.5211) \mathrm{a}$ & $4.1390(.6248) \mathrm{a}$ & $4.2459(.5713) \mathrm{a}$ \\
& Parent support & $3.4194(1.1211) \mathrm{a}$ & $3.8791(.9621) \mathrm{a}, \mathrm{c}$ & $4.0153(1.0114) \mathrm{b}, \mathrm{c}$ & $4.2130(.9257) \mathrm{b}$ \\
Antisocial behaviors & Friend support & $2.8323(.8750) \mathrm{a}$ & $3.2776(.9044) \mathrm{a}$ & $3.1102(.9394) \mathrm{a}$ & $3.1008(1.0472) \mathrm{a}$ \\
& Nonviolent delinquent behavior & $1.3935(.4851) \mathrm{a}, \mathrm{b}$ & $1.3409(.5544) \mathrm{a}, \mathrm{b}$ & $1.3992(.6121) \mathrm{a}$ & $1.2398(.5652) \mathrm{b}$ \\
Academic & Violent behaviors & $1.3548(.4470) \mathrm{a}, \mathrm{b}$ & $1.4340(.6329) \mathrm{a}$ & $1.3878(.6307) \mathrm{a}, \mathrm{b}$ & $1.2706(.4480) \mathrm{b}$ \\
& GPA & $1.5272(.8754) \mathrm{a}, \mathrm{b}$ & $1.5719(.9568) \mathrm{a}, \mathrm{b}$ & $1.4839(.9878) \mathrm{a}$ & $1.8181(.8289) \mathrm{b}$ \\
& Self-reported grade & $5.07(1.97) \mathrm{a}$ & $5.28(2.05) \mathrm{a}$ & $5.09(2.07) \mathrm{a}$ & $4.90(1.82) \mathrm{a}$ \\
\hline
\end{tabular}

Note. Means with same letter are not significantly different using Tukey post hoc, $p<.05$. 
Table II. MANOVA Means (and Standard Deviations) for Wave 5 Variables

\begin{tabular}{|c|c|c|c|c|c|}
\hline & \multicolumn{5}{|c|}{ Stress trajectory } \\
\hline & Variable & High mean & Increasing & Decreasing & Low mean \\
\hline \multirow[t]{3}{*}{ Well-being } & Anxiety & $2.0230(.7220) \mathrm{a}$ & $1.8023(.6016) \mathrm{a}$ & $1.4772(.5014) b$ & $1.3362(.4764) b$ \\
\hline & Depression & $2.4828(.9609) \mathrm{a}$ & $2.0620(.6932) \mathrm{b}$ & $1.5499(.5077) \mathrm{c}$ & $1.4379(.5516) \mathrm{c}$ \\
\hline & John Henryism & $3.9267(.6370) \mathrm{a}$ & $4.0310(.6052) \mathrm{a}$ & $4.2853(.5512) b$ & $4.4883(.5879) \mathrm{c}$ \\
\hline \multirow[t]{3}{*}{ Support } & Mother support & $3.4222(1.2212) \mathrm{a}$ & $3.7143(1.0931) \mathrm{a}$ & $4.2464(.8830) b$ & $4.3210(.8275) \mathrm{b}$ \\
\hline & Father support & $2.8556(1.3768) \mathrm{a}$ & $2.8791(1.2062) \mathrm{a}$ & $3.1403(1.1622) \mathrm{a}$ & $3.2444(1.1942) \mathrm{a}$ \\
\hline & Friend support & $2.5667(1.1887) \mathrm{a}$ & $3.2769(.9366) \mathrm{b}$ & $3.3325(.9140) \mathrm{b}$ & $3.4272(.8395) b$ \\
\hline \multirow[t]{2}{*}{ Antisocial behavior } & Nonviolent delinquent behavior & 1.2605 (.4296) a,b & $1.2282(.4981) \mathrm{a}$ & $1.1801(.3914) \mathrm{a}, \mathrm{b}$ & $1.0980(.2604) \mathrm{b}$ \\
\hline & Violent behavior & $1.4631(.6211) \mathrm{a}$ & $1.2681(.4357) \mathrm{a}, \mathrm{b}$ & $1.2537(.4124) \mathrm{a}, \mathrm{b}$ & $1.1801(.3661) b$ \\
\hline \multirow[t]{2}{*}{ Academic } & Highest grade completed & $4.0435(1.6646) \mathrm{a}$ & $4.4513(1.6690) \mathrm{a}$ & $4.5258(1.7683) \mathrm{a}$ & $5.1531(1.3188) b$ \\
\hline & Graduation status & $1.22(.90) \mathrm{a}$ & $1.19(.90) \mathrm{a}$ & $1.20(.91) \mathrm{a}$ & $0.98(.93) \mathrm{a}$ \\
\hline
\end{tabular}

Note. Means with same letter are not significantly different using Tukey post hoc, $p<.05$.

5.531, $p<0.01)$, but no interaction effect for cluster groups by $\operatorname{sex}(F(6,792)=1.582, \mathrm{~ns})$ were found. A main effect of cluster group was found for parental support, $F(3,406)=6.133, p<0.01$. Those in the High group had less parental support than those in the Decreasing and Low groups, whereas those in the Low group had more parental support than those in the High and Increasing groups. Females reported more friend support than males $(F(1,406)=6.363, p<0.05)$.

\section{Delinquency}

Cluster group (Hotelling's Trace $F(6,790)=2.312$, $p<0.05)$ and $\operatorname{sex}(F(2,396)=5.931, p<0.01)$ main effects were found, whereas no interaction of cluster group by $\operatorname{sex}(F(6,790)=0.681$, ns) was found. A main effect of cluster group for nonviolent delinquent behavior $(F(3,405)=2.892, p<0.05)$ was found, while the main effect for violent behavior was a trend $(F(3,405)=$ $2.273, p<0.10$ ). Tukey post hoc tests showed a trend for more reports of nonviolent delinquent behavior in the Decreasing group than the Low group, and a trend for more reports of violent behavior in the Increasing group than the Low group. Males reported more nonviolent delinquency $(F(1,405)=9.813, p<0.01)$, but not violent behavior, than females.

\section{Academic Success}

Multivariate tests found a trend for a cluster group main effect (Hotelling's Trace $F(6,740)=1.934, p<$ $0.10)$, but no main effect for $\operatorname{sex}(F(2,371)=1.463$, ns $)$, or sex by cluster group interaction $(F(6,740)=1.417, \mathrm{~ns})$ was found. In univariate analyses, a main effect by cluster was found for GPA $(F(3,380)=3.513, p<0.05)$, but not for self-reported grade. Those in the Low group had higher GPAs than those in the Decreasing group.

\section{Outcomes of Stress Trajectories}

Two (sex) by four (stress group) MANOVAs were run on each set of the well-being, support, antisocial behaviors, and academic success variables at Wave 5 to assess the consequences of trajectories during high school on young adult outcomes. The means and standard deviations for these analyses are reported in Table II.

\section{Psychological Well-Being}

Multivariate main effects were found for cluster group (Hotelling's Trace $F(9,1145)=13.410, p<0.01$ ), but not for $\operatorname{sex}(F(3,383)=0.728$, ns $)$, or sex by cluster group interaction $(F(9,1145)=0.651, \mathrm{~ns})$. In univariate analyses, main effects by cluster were found for all variables in this category. For anxiety $(F(1,393)=17.871$, $p<0.01$ ), those in the High and Increasing groups reported more anxiety than those in the Decreasing and Low groups. For depression $(F(1,393)=31.219, p<0.01)$, the High group reported the most depression and the Increasing group reported more depression than the Decreasing and Low groups. An effect for John Henryism was found with this wave of data $(F(1,393)=12.755, p<$ $0.01)$. The Low group reported the most John Henryism and the Decreasing group reported more John Henryism than the Increasing and High groups.

\section{Support}

Main effects for cluster group (Hotelling's Trace $F(9$, $767)=3.325, p<0.01)$ and $\operatorname{sex}(F(3,257)=4.542$, 
Table III. Multivariate Hotelling's $F$ Statistics (df) for Analyses Comparing the Increasing and Decreasing Stress Groups

\begin{tabular}{lrccc}
\hline & Wave 1 & Wave 3 & Wave 4 & Wave 5 \\
\hline Psychological well-being & $.219(3,247)$ & $.678(3,248)$ & $2.834^{*}(3,246)$ & $16.893^{* *}(3,243)$ \\
Support & $1.977(2,251)$ & $1.912(3,196)$ & $1.969(3,189)$ & $3.997^{* *}(3,165)$ \\
Antisocial behavior & $1.834(2,250)$ & $.291(2,249)$ & $.420(2,248)$ & $.417(2,244)$ \\
Academics & $.958(2,231)$ & $3.492^{*}(2,172)$ & $.193(2,117)$ & $.907(2,209)$ \\
\hline
\end{tabular}

${ }^{*} p<.05 ; * * p<.01$.

$p<0.01)$ were found. No sex by cluster group interaction was found $(F(9,767)=0.625, \mathrm{~ns})$. Univariate main effects by cluster were found for mother support $(F(3$, $267)=5.990, p<0.01)$ and friend support $(F(3,267)=$ $4.449, p<0.01)$. Mother support was higher in the Decreasing and Low groups than the Increasing and High groups. Friend support was lower in the High group than all other groups. Males reported more father support than females $(F(1,267)=9.879, p<0.05)$.

\section{Delinquency}

Multivariate main effects were found for cluster group (Hotelling's Trace $F(6,768)=3.418, p<0.01$ ) and $\operatorname{sex}(F(2,385)=12.369, p<0.01)$. No sex by cluster group interaction effect was found $(F(6,768)=1.950$, ns). Univariate main effects by cluster were found for both nonviolent delinquent behavior $(F(3,394)=5.618$, $p<0.01)$ and violent behavior $(F(3,394)=4.081, p<$ 0.01 ). The Increasing group reported more nonviolent behavior than the Low group, and the High group reported more violent behavior than the Low group. Males reported more of both nonviolent behavior $(F(1,394)=24.780$, $p<0.01)$ and violent behavior $(F(1,394)=7.575, p<$ $0.01)$ than females.

\section{Academic Success}

A multivariate main effect was found for cluster group (Hotelling's Trace $F(6,642)=3.306, p<0.01$ ), but no main effect for sex $(F(2,322)=1.721$, ns) or sex by cluster group interaction was found $(F(6,642)=$ $1.568, \mathrm{~ns})$. Univariate main effects by cluster were found for highest grade completed, $F(3,331)=5.505, p<$ 0.01 , but not for school reported graduation status, $F(3$, $331)=1.748$, ns. The Low group showed the highest grade completed than all other groups (equivalent to between a high school diploma and 1 year of college, whereas the other group means are equivalent to less than a high school diploma).

\section{Differences Between the Increasing and Decreasing Stress Groups Over Time}

We also compared only the Increasing and Decreasing groups in Waves 1, 3, 4, and 5 on the well-being, support, antisocial behaviors, and academic success variables to examine differences over time to explain the divergence of the paths between Waves 3 and 4 (see Fig. 1). These time points were chosen because we wished to examine if there were any differences before their paths diverged (Wave 1), immediately before their paths diverged (Wave 3), over the time period when the divergence began (Wave 4), and for final outcomes (Wave 5). Multivariate Hotelling's Trace $F$ 's are reported in Table III. Univariate $F$ 's are reported below. We found no differences between groups at Wave 1 for any study variable. Only GPA $(F(1,175)=6.944$, $p<0.01$ ) differed at Wave 3, with the Decreasing group reporting lower GPA than the increasing group. When the 2 groups had diverged at Wave 4 , we found that the Increasing group reported higher anxiety $(F(1,250)=5.338$, $p<0.05)$ and depression $(F(1,250)=5.949, p<0.05)$ than the Decreasing group. The groups differed on these variables at Wave 5 as well (anxiety, $F(1,247)=20.718$, $p<0.01$; depression, $F(1,247)=43.809, p<0.01)$. In addition, the Decreasing group reported higher John Henryism $(F(1,247)=11.857, \quad p<0.01)$ and more mother support $(F(1,169)=11.855, p<0.01)$ than the Increasing group.

\section{DISCUSSION}

Our results suggest that an examination of perceived stress over time and consideration of within-group variation in patterns of stress may provide valuable insights into the potentially negative effects of stress on psychological and behavioral health. The total sample showed only a slight change in stress over time, but this may not adequately represent adolescents' experience of stress. We found almost $60 \%$ of the youth reported either consistently low or decreasing stress over time. Our results also indicated, however, that $40 \%$ of the youth were chronically 
stressed or increasing their levels over time to eventually come close to matching the chronically stressed group. Notably, females were more likely to report chronic stress than males, but this effect did not differ across stress trajectory (i.e., sex by cluster interaction).

Our findings suggest that those youth who report the lowest levels of anxiety and depression and have the highest GPAs in 9th grade, are likely to have consistently low stress levels. Additionally, adolescents with chronically high or increasing stress during high school tend to have had less parental support and exhibit more antisocial behaviors in 9th grade than youth with decreasing or consistently low stress. These results persist in the 5th wave of the study, where anxiety, depression, nonviolent delinquent behaviors, and violent behaviors are lowest in the low stress group, and mother and friend support are highest in the low stress group. Additionally, John Henryism is greater in the low and decreasing groups, and those in the low group are more likely to have graduated high school and had further education or training. Notably, psychological well-being and support differed across the 2 diverging groups after these groups diverged in stress levels.

The fact that the high stress group reported the highest levels of anxiety and depression, and the low stress group reported the lowest anxiety and depression, is consistent with previous cross-sectional research (Conger et al., 1994; DuBois et al., 1994; Licitra-Kleckler and Waas, 1993; Windle and Windle, 1996). Our results suggest that not just chronic high or low levels of stress are related to psychosocial outcomes as expected, but changing levels of stress are relevant as well. The increasing stress group looks more like the high stress group by Wave 5, whereas the decreasing stress group looks more like the low stress group in terms of psychological well-being, social influences, and antisocial behavior. These results suggest that perceived stressors may have fleeting effects as long as they are not persistent over time. They also provide evidence that lowering perceived stress may be an effective approach to prevent its long-term deleterious effects.

Our measure of active coping was higher in the low and decreasing stress groups in the later waves. In other studies, active coping was related to hypertension and other measures of the detrimental effects of stress (Jackson and Adams-Campbell, 1994; James, 1994). Our results, however, most closely match those of women in the rural South, who were identified as active copers (Dressler $e$ t al., 1998). James (1994) suggested that context has a considerable effect on whether the belief in hard work and active coping is adaptive or maladaptive. It is possible that these beliefs may be adaptive for urban African American adolescents and young adults because they may not have yet experienced the type of institutional discrimination that may limit their avenues for success. It is also possible that their opportunities have not been curtailed by institutional racism so their efforts to actively cope are more likely to be effective.

This study provides additional evidence that emotional support has a direct relationship with stress. Other researchers have found that emotional and instrumental support from parents diminishes the effects of stress on the cardiovascular, endocrine, and immune systems (Strogatz and James, 1986; Uchino et al., 1996). One explanation may be that those with consistently high stress receive less support, which may influence their stress levels, or perhaps parent support is not effective for decreasing stress among youth who are already highly stressed. Those in the low or decreasing stress groups may benefit more from parental support than the high stress group because the effects of stress may be manageable. Alternatively, it is possible that the support helps protect youth from feeling stressed.

We also found some effect of chronic or increasing stress on delinquency. These data suggest that early delinquency is related to a trajectory of high or increasing stress, with less support for a cross-sectional effect. These findings add to a literature that has found mixed results on the relationship between delinquency and stress among African American youth. While some researchers have reported an association between these variables (McCabe et al., 1999), others have not (Dornbusch et al., 1991; Smith and Krohn, 1995). Our results support the notion that delinquency may increase perceived stress among adolescents, and that delinquency does not provide an outlet to reduce feelings of stress. One interpretation of this finding is that getting into trouble or behaving in an antisocial fashion is actually a stressor for adolescents. This behavior involves them with authorities, puts them at odds with adult expectations, and may marginalize them among most of their peers.

Our finding that the low stress group had a higher GPA and were more likely to have gone further with their education than those in groups that had experienced more stress is also consistent with previous research (Dornbusch et al., 1991; Gillock and Reyes, 1999; Windle and Windle, 1996). Notably, the results suggest that GPA may not drive feelings of stress because the changing groups did not differ from any other group. One interpretation of this finding is that previous grades influence subsequent stress. Previous grades and current stress may be collinear as previous grades may account for the concurrent association between stress and grades. This result might also be explained by the relatively low achieving nature of our sample in 8th grade where school success may not be a vital aspect of their well-being. Yet, by 12th grade the 
sample included many A and B students so this seems to be a less plausible explanation. This study supports the notion that school achievement may not be a stressor for urban African American youth. On the contrary, school success seems to be related to less stress.

Our examination of the diverging paths (Increasing and Decreasing) demonstrated that changes in levels of stress are related to changes in levels of psychopathology and support. This divergence at a time when adolescents are preparing to leave high school and are making choices about their life paths is especially critical to study. The post-high school years are marked by instability in many life areas such as education, work, residential status, and relationships (Arnett, 2000). Any period of transition is a time of developmental opportunity and risk (Lerner et al., 1996). The timing associated with making any transition may have an effect on the experience of the transition and have long-term effects on the individual (Graber et al., 1996). While we could not examine what transitions our respondents may have made between Waves 3 and 4 that might have caused the divergence in paths, we do know that an increase in perceived stress was related to current and later increases in depression and anxiety and decreases in support and coping. Thus, longterm monitoring of stress could be helpful for determining when an intervention might be most helpful for adolescents.

The sex differences in stress trajectories are consistent with the findings reported by Licitra-Kleckler and Waas (1993) who found more females than males in their high stress group. Females may have reported more stress than males because they were more honest about their perceptions of stress or are more attuned to stress in their lives. Males may attribute a lack of control over hassles in their lives to what life is supposed to be like, and discount this as not stressful, whereas females may assess these issues as inherently more stressful and may be more likely to experience emotional distress (Dohrenwend and Dohrenwend, 1976; Licitra-Kleckler and Waas, 1993). Alternatively, developmental stressors during the years of late high school and transition out of high school may affect women more than men (Gillock and Reyes, 1999; Tolan, 1988). While exposure to community and domestic violence, and risk for emotional distress related to economic hardship may be similar for both males and females in urban communities (Conger et al., 1999), females may be more likely to develop PTSD which is related to the level of trauma experienced (Horowitz et al., 1995), and more depression, substance use, school failure and suspension, and arrest than those without PTSD (Lipschitz et al., 2000). Thus, the urban environment and possible posttraumatic stress disorder (PTSD) within our sample may have also increased the number of females in the high stress group. The overall sex differences found in our study, however, are consistent with past research on psychological wellbeing (Licitra-Kleckler and Waas, 1993) and delinquent behaviors (Windle and Windle, 1996).

Several limitations of the study should be noted. One limitation is that the stress groups were not equal in size. This may have resulted in relatively low power to detect group differences especially because the high stress group was about one-quarter the size of the other groups. Our findings, however, suggest that the effects of high levels of stress may be particularly robust because, even with limited sample size, this group consistently indicated the most deleterious outcomes. In addition, our results were consistent with hypothesized relationships.

Another limitation is that our sample may not be generalizable to all African American youth, because the respondents were initially selected to participate on the basis of low GPA. This characteristic of the sample may have resulted in limited variance in some study variables, thereby further reducing the chances to find group differences. Yet, not only did the sample include a wide range of GPAs by 12th grade (Zimmerman et al., 2002), but school factors, as noted above, may not be the most pertinent issue for youth in our sample. Future research with a more representative sample, however, would be useful to further develop our understanding of stress trajectories among African American adolescents.

Our findings may also not be generalizable to all forms of social support. Our support measure examined only emotional support from parents and friends. The respondents could have been receiving emotional support from other relatives. In addition, our measure was somewhat narrow and did not assess network structure or other functional mechanisms. Future research would benefit from measures of support that include more types of support and structural characteristics of the support network. Nevertheless, our findings suggest that additional research that examines the mechanism of support in relation to experiences of stress in more detail would be beneficial.

One concern with longitudinal analyses is that giving the same assessment over time may be problematic. Respondents may recall questions from previous interviews and give similar responses without assessing if those responses are currently accurate. After examining the cluster structure, however, individual trajectories maintain significant differences over time. The stress trajectories are distinct and the findings across different psychosocial outcomes also lend support to the idea that testing effects do not explain the results. In addition, a significant number of youth had trajectories that changed over time, 
indicating less probability of simply repeating earlier responses.

Finally, the study is based on self-report data. Although several researchers have noted that perceived stress is relevant for health outcomes regardless of some measure of objective stress (Jackson et al., 1999; Miller, 1999), future research that includes physiological measures of stress, such as cortisol levels, would be beneficial. This would not only help avoid method bias, but also provide vital information about the similarities and differences in perceived and physiological measures. Our outcome measures, though also self-report, do include both selfperceptions and behavioral reports. The implication of this is that youth may not accurately report their feelings or behaviors. The tendency for respondents to report in socially desirable ways, for example, may reduce the variance available to explain in the dependent variables. This, however, would have the effect of reducing our chances to find group differences, but we found meaningful differences across several outcome measures. This enhances our confidence that the results cannot be explained away simply by similar method variance alone.

In conclusion, we found that individuals may have differing trajectories of stress over time, either consistent patterns or displaying change over time. Adolescents with chronic levels of stress are more likely to report more anxiety and depression, to engage in antisocial behaviors and in less active coping. Adolescents with low levels of stress have fewer psychological problems, perceive more social support, and are more likely to graduate high school than those with higher stress levels. Finally, an increase in stress coincides with a lack of support and more psychological problems over time. The longitudinal nature of this study and a person-oriented approach has allowed us to examine more fully the relationship of perceived stress to psychosocial outcomes and behaviors. This patternoriented approach strengthens hypotheses about the role of stress in psychosocial problems and behaviors, which could not be done using a total sample variable-oriented approach. This study also expanded research on stress to an African American sample, which has been historically understudied. Our results suggest that youth report differing levels of stress over time, and that the antecedents and consequences of these trajectories differ as well. This study provides evidence that future research that considers individual differences in patterns of stress over time will provide valuable insights for developing interventions to prevent the negative effects of stress on adolescent development, mitigate those factors that may increase stress, and promote factors that help youth adapt to the stress they will inevitably face as they develop into young adults.

\section{ACKNOWLEDGMENTS}

This research was funded by the National Institute on Drug Abuse, Grant No. DA07484. The views or policies expressed do not necessarily reflect the views or policies of the National Institute on Drug Abuse. We thank the school officials, the Program for Urban and Regional Affairs at the University of Michigan, Flint, and the youths who participated in the research. We also thank the reviewers for their thoughtful comments on earlier drafts of this manuscript.

\section{REFERENCES}

Arnett, J. J. (2000). Emerging adulthood: A theory of development from the late teens through the twenties. Am. Psychol. 55(5): 469-480.

Carlson, C., Uppal, S., and Prosser, E. C. (2000). Ethnic differences in processes contributing to the self-esteem of early adolescent girls. J. Early Adolesc. 20(1): 44-67.

Chrousos, G. P., and Gold, P. W. (1992). The concepts of stress and stress system disorders. JAMA 267: 1244-1252.

Cohen, S. (1988). Psychosocial models of the role of social support in the etiology of physical disease. Health Psychol. 7(3): 269-297.

Cohen, S., Kamarck, T., and Mermelstein, R. (1983). A global measure of perceived stress. J Health Soc. Behav. 24: 385-396.

Conger, R. D., Conger, K. J., Matthews, L. S., and Elder, G. H. (1999). Pathways of economic influence on adolescent adjustment. Am. J. Community Psychol. 27(4): 519-541.

Conger, R. D., Ge, X., Elder, G. H., Lorenz, F. O., and Simons, R. L. (1994). Economic stress, coercive family process, and developmental problems of adolescents. Child Dev. 65: 541-561.

Derogatis, L. R., and Spencer, P. M. (1982). The Brief Symptom Inventory (BSI): Administration and Scoring Procedures. Division of Medical Psychology, Johns Hopkins University School of Medicine, Baltimore, MD.

Dohrenwend, B. P., and Dohrenwend, B. S. (1976). Sex differences and psychiatric disorders. Am. J. Sociol. 81: 1447-1454.

Dornbusch, S. M., Mont-Reynaud, R., Ritter, P. L., Chen, Z., and Steinberg, L. (1991). Stressful events and their correlates among adolescents of diverse backgrounds. In Colton, M. E., and Gore, S. (eds.), Adolescent Stress: Causes and Consequences. Aldine de Gruyter, New York, pp. 111-130.

Dressler, W. W., Bindon, J. R., and Neggers, Y. H. (1998). John Henryism, gender, and arterial blood pressure in an African American community. Psychosom. Med. 60: 620-624.

DuBois, D. L., Felner, R. D., Meares, H., and Krier, M. (1994). Prospective investigation of the effects of socioeconomic disadvantage, life stress, and social support on early adolescent adjustment. J. $A b$ norm. Psychol. 103(3): 511-522.

Gillock, K. L., and Reyes, O. (1999). Stress, supports, and academic performance of urban, low-income, Mexican-American adolescents. $J$. Youth Adolesc. 28(2): 259-282.

Graber, J. A., Brooks-Gunn, J., and Petersen, A. C. (1996). Adolescent transitions in context. In Graber, J. A., Brooks-Gunn, J., and Petersen, A. C. (eds.), Transitions Through Adulthood: Interpersonal Domains and Context. Erlbaum, Mahwah, NJ, pp. 369-383.

Hastings, T., Anderson, S. J., and Hemphill, P. (1997). Comparisons of daily stress, coping, problem behavior, and cognitive distortions in adolescent sexual offenders and conduct-disordered youth. Sex. Abuse J. Res. Treatment 9(1): 29-42.

Horowitz, K., Weine, S., and Jekel, J. (1995). PTSD symptoms in urban adolescent girls: Compounded community trauma. J. Am. Acad. Child Adolesc. Psychiatry 34(10): 1353-1361. 
Jackson, L. A., and Adams-Campbell, L. L. (1994). John Henryism and blood pressure in black college students. J. Behav. Med. 17(1): 6979.

Jackson, R. W., Treiber, F. A., Turner, J. R., Davis, H., and Strong, W. B. (1999). Effects of race, sex, and socioeconomic status upon cardiovascular stress responsivity and recovery in youth. Int. J. Psychophysiol. 31(2): 111-119.

James, S. A. (1994). John Henryism and the health of AfricanAmericans. Culture Med. Psychiatry 18: 163-182.

James, S. A., Hartnett, S. A., and Kalsbeek, W. D. (1983). John Henryism and blood pressure differences among black men. J. Behav. Med. 6: 259-278.

James, S. A., Keenan, N. L., Strogatz, D. S., Browning, S. R., and Garrett, J. M. (1992). Socioeconomic status, John Henryism, and blood pressure in black adults. Am. J. Epidemiol. 135(1): 59-67.

James, S. A., Strogatz, D. S., Wing, S. B., and Ramsey, D. L. (1987). Socioeconomic status, John Henryism, and hypertension in Blacks and Whites. Am. J. Epidemiol. 126: 664-673.

Landrine, H., and Klonoff, E. A. (1996). The schedule of racist events: A measure of racial discrimination and a study of its negative physical and mental health consequences. J. Black Psychol. 22(2): 144168.

Lerner, R. M., Lerner, J. V., von Eye, A., Ostrom, C. W., Nitz, K., TalwarSoni, R., \& Tubman, J. G. (1996). Continuity and discontinuity across the transition of early adolescence: A developmental contextual perspective. In Graber, J. A., Brooks-Gunn, J., and Petersen, A. C. (eds.), Transitions Through Adulthood: Interpersonal Domains and Context. Erlbaum, Mahwah, NJ, pp. 3-22.

Licitra-Kleckler, D. M., and Waas, G. A. (1993). Perceived social support among high-stress adolescents: The role of peers and family. $J$. Adolesc. Res. 8(4): 381-402.

Lipschitz, D. S., Rasmusson, A. M., Anyan, W., Cromwell, P., and Southwick, M. D. (2000). Clinical and functional correlations of posttraumatic stress disorder in urban adolescent girls at a primary care clinic. J. Am. Acad. Child Adolesc. Psychiatry 39(9): 11041111.

McBurnett, K., Lahey, B. B., Rathouz, P. J., and Loeber, R. (2000). Low salivary cortisol and persistent aggression in boys referred for disruptive behavior. Arch. Gen. Psychiatry 57: 38-43.

McCabe, K. M., Clark, R., and Barnett, D. (1999). Family protective factors among urban African American youth. J. Clin. Child Psychol. 28(2): 137-150.

Miller, D. B. (1999). Racial socialization and racial identity: Can they promote resiliency for African American adolescents? Adolescence 34: 493-501.

Procidano, M. E., and Heller, K. (1983). Measures of perceived social support from friends and from family: Three validation studies. Am. J. Community Psychol. 11: 1-24.

Raine, A., O'Brien, M., Smiley, N., Scerbo, A., and Chan, C. (1990). Reduced lateralization in verbal dichotic listening in adolescent psychopaths. J. Abnorm. Psychol. 99: 272-277.
Rutter, M. (1993). Resilience: Some conceptual considerations. J. Adolesc. Health 14: 626-631.

Scerbo, A. S., and Kolko, D. J. (1994). Salivary testosterone and cortisol in disruptive children: Relationship to aggressive, hyperactive, and internalizing behaviors. J. Am. Acad. Child Adolesc. Psychiatry 33(8): 1174-1184.

Smith, E. M. J. (1985). Ethnic minorities: Life stress, social support, and mental health issues. Counsel. Psychol. 13(4): 537-579.

Smith, C., and Krohn, M. D. (1995). Delinquency and family life among male adolescents: The role of ethnicity. J. Youth Adolesc. 24(1): 69-93.

Strogatz, D. S., and James, S. (1986). Social support and hypertension among blacks and whites in a rural, southern community. Am. $J$. Epidemiol. 124(6): 949-956.

Susman, E. J., Dorn, L. D., Inoff-Germain, G., Nottelman, E. D., and Chrousos, G. P. (1997). Cortisol reactivity, distress behavior, and behavioral and psychological problems in young adolescents: A longitudinal perspective. J. Res. Adolesc. 7(1): 81-105.

Susman, E. J., Granger, D. A., Murowchick, E., Ponirakis, A., and Worrall, B. K. (1996). Gonadal and adrenal hormones: Developmental transitions and aggressive behavior. Ann. N. Y. Acad. Sci. 794: 18-30.

Sutton, S. E., Cowen, E. L., Crean, H. F., and Wyman, P. A. (1999). Pathways to aggression in young, highly stressed urban children. Child Study J. 29(1): 49-67.

Tolan, P. (1988). Socioeconomic, family, and social stress correlates of adolescent antisocial and delinquent behavior. J. Abnorm. Child Psychol. 16(3): 317-331.

Uchino, B. N., Cacioppo, J. T., and Kiecolt-Glaser, J. K. (1996). The relationship between social support and physiological processes: A review with emphasis on underlying mechanisms and implications for health. Psychol. Bull. 119(3): 488-531.

Weist, M. D., Freedman, A. H., Paskewitz, D. A., Proescher, E. J., and Flaherty, L. T. (1995). Urban youth under stress: Empirical identification of protective factors. J. Youth Adolesc. 24(6): 705-721.

White, K. S., Bruce, S. E., Farrell, A. D., and Kliewer, W. (1998). Impact of exposure to community violence on anxiety: A longitudinal study of family social support as a protective factor for urban children. $J$. Child Fam. Stud. 7(2): 187-203.

Windle, M., and Windle, R. C. (1996). Coping strategies, drinking motives, and stressful life events among middle adolescents: Associations with emotional and behavioral problems and with academic functioning. J. Abnorm. Psychol. 105(4): 551-560.

Zimmerman, M. A., Ramirez-Valles, J., Zapert, K. M., and Maton, K. I. (2000). A longitudinal study of stress-buffering effects for urban African-American male adolescent problem behaviors and mental health. J. Commun. Psychol. 28(1): 17-33.

Zimmerman, M. A., Caldwell, C. H., and Bernat, D. H. (2002). Discrepancy between self-report and school-record grade point average: Correlates with psychosocial outcomes among African American adolescents. J. Appl. Soc. Psychol. 32(1), 86-109. 